\title{
Value of M-mode echocardiography for non-invasive diagnosis of Ebstein's anomaly
}

\author{
W DANIEL, P RATHSACK, G WALPURGER, A KAHLE, R GISBERTZ, \\ J SCHMITZ, P R LICHTLEN
}

From the Division of Cardiology, Department of Medicine, and the Division of Cardiology, Department of Pediatrics, Hannover Medical School, Hannover, Federal Republic of Germany

SUMMARY $M$-mode echocardiographic studies were performed in 11 patients, most of them adults, with Ebstein's anomaly of the tricuspid valve, proven by cardiac catheterisation. Simultaneous recordings of the tricuspid and mitral valves were obtained in all cases, the transducer position being outside the left midclavicular line in seven patients. Tricuspid valve closure followed mitral valve closure in all cases, with an interval ranging between 0.04 and $0.14 \mathrm{~s}$. Since, in more than 8500 routine echocardiographic studies a valve closure interval between 0.09 and $0.12 \mathrm{~s}$ was seen in only one patient without Ebstein's anomaly, an interval of $0.065 \mathrm{~s}$ or more should be regarded as diagnostic of Ebstein's disease; however, an interval shorter than $0.065 \mathrm{~s}$ does not exclude this diagnosis.

In all patients a paradoxical septal movement was found. Two patients showed an atypical threepeaked diastolic pattern of movement of the anterior tricuspid leaflet and one patient also showed mitral valve prolapse.

Pathological tricuspid valve closure delay, shown by echocardiography, makes it possible to diagnose Ebstein's anomaly in many cases without resort to cardiac catheterisation which has a relatively high risk in this disease.

The tricuspid valve anomaly first described by Ebstein in $1866^{1}$ is found in less than 1 per cent of patients with congenital malformations of the heart. ${ }^{2}$ The principal anatomical lesion consists of a downward displacement of varying degree of the septal and posterior leaflets of the tricuspid valve. The clinical course, radiological, electrocardiographic, and phonocardiographic findings, and prognosis are well known. ${ }^{3-5}$ Cardiac catheterisation and angiocardiography usually confirm the suspected clinical diagnosis; however, in this condition, these procedures are associated with an increased risk, with mortality of approximately 3.5 per cent. ${ }^{5}$ Echocardiography, a non-invasive diagnostic method with a high degree of accuracy, is thus of special importance in this disease.

Since Lundström's first description in 1969, Mmode echocardiographic findings in Ebstein's anomaly have been described ${ }^{6-14}$; however, most of these authors reported only a few cases and only a few tried to analyse the echocardiographic features systematically. As the results of these studies were inconsistent, particularly in respect of the pattern Received for publication 27 March 1979 of movement of the tricuspid valve, the echocardiographic signs of this anomaly were carefully analysed in seven adults and four children; all of whom had had cardiac catheterisation in our laboratory during recent years.

\section{Subjects and methods}

\section{PATIENTS}

Eleven patients were studied (seven female and four male; aged between 1 and 41 years, average 21 years). The diagnosis of Ebstein's anomaly was confirmed in all by right heart catheterisation (including right ventriculography in eight cases) and in two cases also by necropsy; in seven patients left heart catheterisation was also performed. Five patients had a secundum atrial septal defect, and three a patent foramen ovale (Table 1). At the time of examination, all patients were in sinus rhythm, five with incomplete and six with complete right bundle-branch block.

METHODS

$M$-mode echocardiograms were recorded in the 
Table 1 Echocardiographic measurements in patients with Ebstein's anomaly

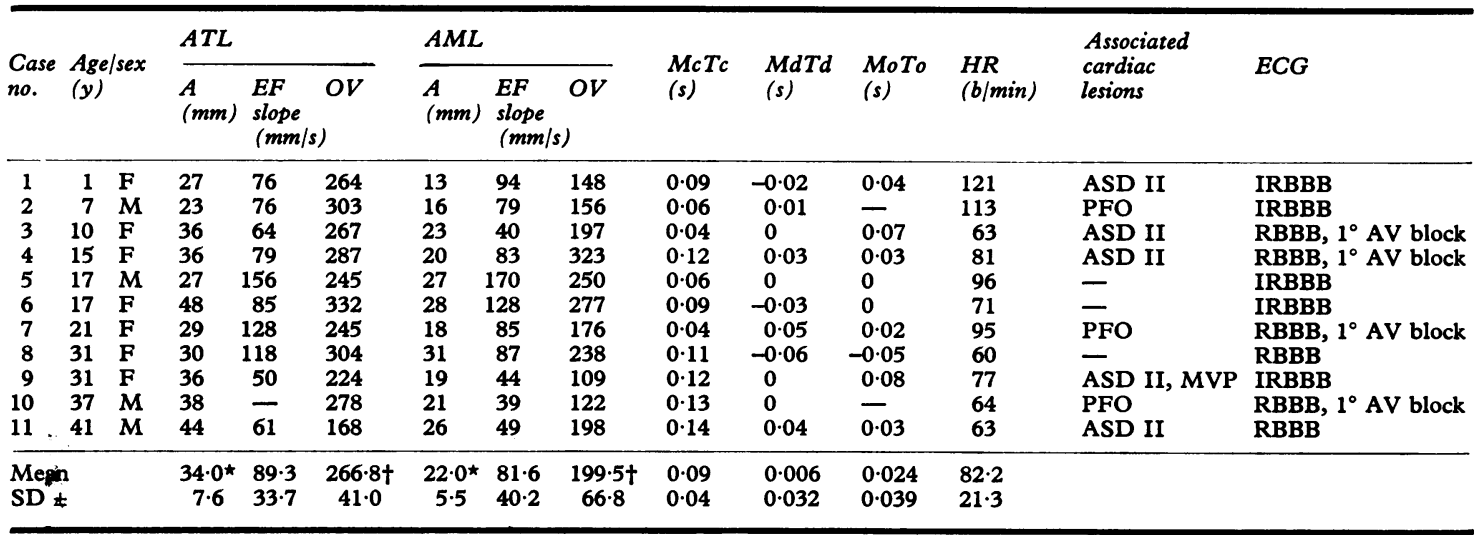

$\star P<0.001 ;+P<0.01$.

ATL and AML, anterior tricuspid and mitral leaflets; A, amplitude; EF slope, early diastolic closing slope; OV, opening velocity; McTc, interval between mitral (Mc) and tricuspid (Tc) valve closure; MdTd, interval between mitral (Md) and tricuspid (Td) valve opening; MoTo, interval between maximal opening of mitral (Mo) and tricuspid (To) valve; HR, heart rate;

PFO, patent foramen ovale; MVP, mitral valve prolapse; ASD II, atrial septal defect (secundum type); RBBB, right bundle-branch block; IRBBB, (incomplete) right bundle-branch block; $1^{\circ} \mathrm{AV}$ block, first degree AV block.

supine position with a 2.25 or $4.5 \mathrm{MHz}$ focused or unfocused transducer using an Echocardiovisor 01 (Organon Teknika, OSS/Netherlands), a SmithKline Ekoline 20, or an Irex ultrasonoscope. Recordings were made at paper speeds of 50 and $100 \mathrm{~mm} / \mathrm{s}$ on high-sensitivity photographic paper. In all patients simultaneous recordings of the anterior tricuspid leaflet and the anterior mitral leaflet were obtained. For this purpose in seven cases an unusual left lateral transducer position was necessary up to the anterior axillary line.

In order to compare our results with those of other investigators, ${ }^{812}$ the following points were defined (Fig. 1): point ' $d$ ' indicating the beginning of the rapid diastolic opening movement or the end of the slow systolic anterior motion of the anterior leaflets of tricuspid ( $T$ ) and mitral $(M)$ valves ( $\mathrm{Td}$ and $\mathrm{Md}$ ); point 'o' corresponding to the most anterior position of the anterior leaflets at the time of complete opening of each valve (To and Mo); point ' $c$ ' representing the most posterior position at the end of diastole or the beginning of systole with closure of the leaflets ( $\mathrm{Tc}$ and $\mathrm{Mc}$ ).

From these points, the closing interval (McTc), the opening interval (MdTd), and the interval at maximal opening (MoTo) were measured. In addition, the opening amplitude ' $A$ ' (maximal distance $c-0$ ), the opening velocity $(d-0)$, and the early diastolic closing slope (EF slope, beginning at point ' $o$ ') were measured. End-diastolic diameters (EDD) of the right and the left ventricle were measured at the peak of the $R$ wave of the simultaneously recorded electrocardiogram. Measurements were averaged over three to five cardiac cycles. Interventricular septal motion was analysed with regard to abnormal motion type A (systolic

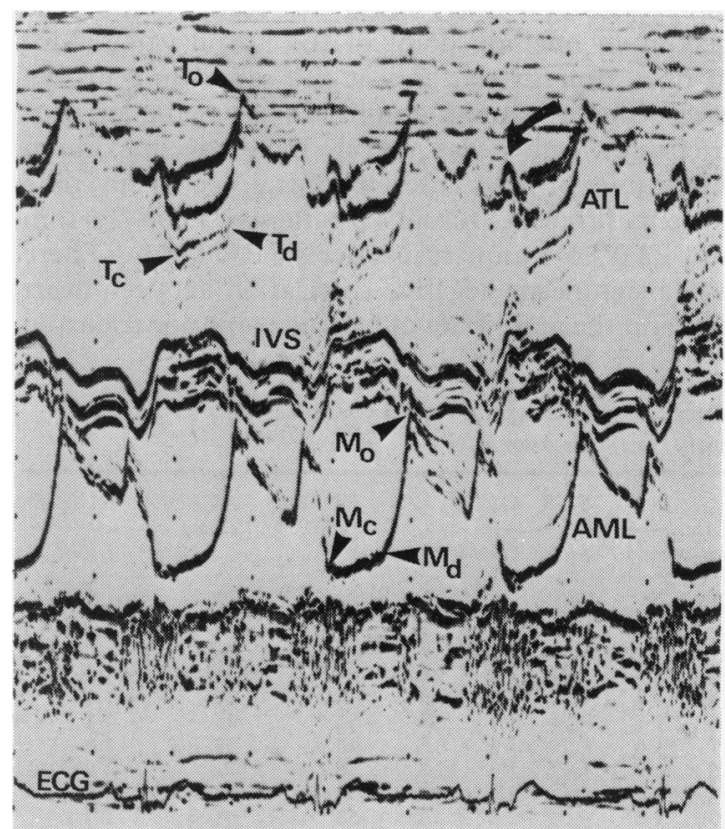

Fig. 1 Echocardiogram in Ebstein's anomaly. ATL and $A M L$, anterior tricuspid and mitral leaflets; IVS, interventricular septum; $T c$ and $M c$, tricuspid and mitral valve closure; Td and $M d$, tricuspid and mitral valve opening; To and Mo, point of maximal opening of tricuspid and mitral valve; arrow, additional diastolic opening movement of ATL (see text). ECG, electrocardiogram. 
anterior movement) and type B (reduced posterior movement). Statistical analysis was performed using standard linear regression and Student's t test.

\section{Results}

The results are summarised in Tables 1 and 2 . In all 11 patients tricuspid valve closure followed mitral valve closure (Fig. 1, 2, 4), the interval McTc varying between 0.04 and $0.14 \mathrm{~s}$ (average $0.09 \pm 0.04 \mathrm{~s}$ ). Simultaneous phonocardiographic recordings showed that the moment of tricuspid and mitral valve closure (Tc, Mc) coincided with the tricuspid and mitral components of the first heart sound (Fig. 2 and 3). No significant linear correlation was found between McTc and the amplitude $(r=0.50)$ or opening velocity of the anterior tricuspid leaflet $(r=-0 \cdot 19)$, RVEDD $(r=0.33)$, or ratio RVEDD/LVEDD $(r=0.23)$.

Tricuspid opening (Td) was found to occur before mitral opening (Md) in three, after in four, and at the same time in four patients. The maximum opening point of the tricuspid valve (To) could not be determined exactly in two cases; in the other nine cases To was found to occur before the maximum opening point of the mitral valve (Mo) in one, after in six, and at the same time in two cases. The maximum amplitude ' $A$ ' of the anterior tricuspid leaflet was larger than the maximum amplitude of the anterior mitral leaflet in nine patients (averages for all 11 patients: $34.0 \pm 7.6 \mathrm{~mm}$ and $22.0 \pm 5.5 \mathrm{~mm}$, respectively; $P<0.001)$. There was a significant negative correlation between heart rate and the amplitude of both the anterior tricuspid

Table 2 Echocardiographic measurements in patients with Ebstein's anomaly

\begin{tabular}{|c|c|c|c|c|c|c|c|}
\hline \multirow{2}{*}{$\begin{array}{l}\text { Case } \\
\text { no. }\end{array}$} & \multirow{2}{*}{$\frac{A T}{A M}$} & \multirow{2}{*}{$\frac{S L T}{S L M}$} & \multirow{2}{*}{$\frac{O V T}{O V M}$} & \multirow[t]{2}{*}{ IVS } & \multirow{2}{*}{$\underset{(\mathrm{mm})}{R V E D D}$} & \multirow{2}{*}{$\begin{array}{l}\text { LVEDD } \\
(\mathrm{mm})\end{array}$} & \multirow{2}{*}{$\frac{R V E D D}{L V E D D}$} \\
\hline & & & & & & & \\
\hline 1 & $2 \cdot 1$ & 0.8 & 1.8 & $\mathbf{A}$ & 28 & 21 & $1 \cdot 3$ \\
\hline 2 & 1.4 & $1 \cdot 0$ & 1.9 & A & 33 & 26 & $1 \cdot 3$ \\
\hline 3 & $1 \cdot 6$ & 1.6 & 1.4 & $\mathbf{A}$ & 59 & 31 & 1.9 \\
\hline 4 & 1.8 & $1 \cdot 0$ & 0.9 & $\mathbf{A}$ & 42 & 31 & 1.4 \\
\hline 5 & 1.0 & 0.9 & $1 \cdot 0$ & $\mathbf{A}$ & 45 & 40 & $1 \cdot 1$ \\
\hline 6 & $1 \cdot 7$ & 0.7 & $1 \cdot 2$ & A & 51 & 45 & $1 \cdot 1$ \\
\hline 7 & 1.6 & 1.5 & $1 \cdot 4$ & A & 40 & 39 & 1.0 \\
\hline 8 & $1 \cdot 0$ & $1 \cdot 4$ & $1 \cdot 3$ & $\mathbf{A}$ & 56 & 31 & 1.8 \\
\hline 9 & 1.9 & $1 \cdot 1$ & $2 \cdot 1$ & $\mathbf{A}$ & 56 & 33 & $1 \cdot 7$ \\
\hline 10 & 1.8 & - & $2 \cdot 3$ & A & 58 & 41 & $1 \cdot 4$ \\
\hline 11 & $1 \cdot 7$ & $1 \cdot 2$ & 0.9 & $\mathbf{A}$ & 53 & 38 & 1.4 \\
\hline \multirow{2}{*}{\multicolumn{2}{|c|}{$\begin{array}{l}\text { Mean } 1.6 \\
S D \pm 0.3\end{array}$}} & $1 \cdot 1$ & 1.5 & & $47 \cdot 4^{\star}$ & $34 \cdot 2^{\star}$ & 1.4 \\
\hline & & 0.3 & 0.5 & & $10 \cdot 5$ & $7 \cdot 1$ & 0.3 \\
\hline
\end{tabular}

$\star P<0.001$.

AT and AM, amplitude of ATL and AML; SLT and SLM, early diastolic closing slope of ATL and AML; OVT and OVM, opening velocity of ATL and AML; IVS A, paradoxical septal movement type A; RVEDD and LVEDD, end-diastolic diameter of right and left ventricle.

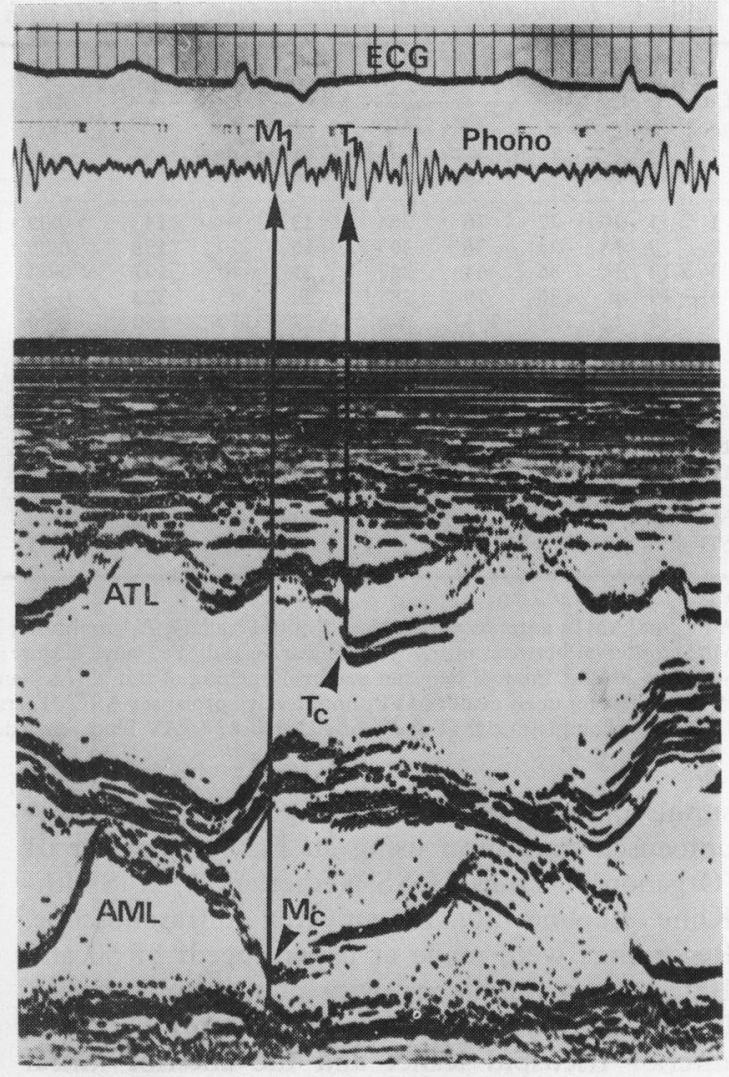

Fig. 2 Echocardiogram in Ebstein's anomaly. McTc interval, $0 \cdot 140$ s. Mc corresponds with mitral (M1), Tc with tricuspid (T1) component of the first heart sound. Phono, external phonocardiogram.

leaflet $(r=-0.71 ; P<0.05)$ and the anterior mitral leaflet $(r=-0.72 ; P<0.05)$.

The early diastolic closing slope of the anterior tricuspid leaflet could not be measured in one case; in three cases this slope was in the lower range of normal or slightly reduced (50 to $64 \mathrm{~mm} / \mathrm{s}$ ). The early diastolic closing slope of the anterior mitral leaflet was similarly slightly reduced in these three cases ( 40 to $49 \mathrm{~mm} / \mathrm{s}$ ). In five patients the closing slope of the anterior tricuspid leaflet was faster than the slope of the corresponding anterior mitral leaflet, ranging between 118 and $156 \mathrm{~mm} / \mathrm{s}$ in three cases; in the remaining five patients the closing slope of the anterior mitral leaflet was faster. In the group as a whole there was no significant difference between the closing slopes (tricuspid $89.3 \pm 33.7 \mathrm{~mm} / \mathrm{s}$, mitral $81.6 \pm 40.2 \mathrm{~mm} / \mathrm{s})$. The linear correlation between the tricuspid and mitral closing slopes was significant $(r=0.77 ; P<0.01)$, but there was no significant correlation between the closing slopes and heart rates. 
Finally, the opening velocity of the anterior tricuspid leaflet (TdTo) was found to be faster than the opening velocity of the anterior mitral leaflet (MdMo) in all but three cases; for the whole group this difference was significant (tricuspid $266.8 \pm 41.0 \mathrm{~mm} / \mathrm{s}$, mitral $199.5 \pm 66.8 \mathrm{~mm} / \mathrm{s} ; \mathrm{P}<$ 0.01 ).

Two patients showed an atypical three-peak movement of the anterior tricuspid leaflet: after the late diastolic opening caused by atrial contraction there was an additional opening motion before closure (Fig. 1 and 4).

In all 11 patients RVEDD was larger than LVEDD $(47.4 \pm 10.5 \mathrm{~mm}$ vs. $34.2 \pm 7.1 \mathrm{~mm} ; \mathrm{P}<$ 0.001 ), the ratio RVEDD/LVEDD ranging from 1.0 to 1.9 . In all patients paradoxical septal movement type A was present.

As an incidental finding one patient showed a conspicuous prolapse of the posterior mitral leaflet on the left ventriculogram, though this was not convincingly shown on the echocardiogram.

\section{Discussion}

As a rule in this group of patients it was much easier to locate the anterior tricuspid leaflet than the anterior mitral leaflet, as is usually the case in diseases with right ventricular volume overload. Moreover, in the majority of cases, the transducer position for optimal display of both valves was found to be outside the left midclavicular line. This is in accord with the findings of Farooki et al. ${ }^{12}$ who studied more than 2000 neonates and infants with normal hearts and different congenital malforma- tions; these authors considered the ability to record the anterior tricuspid leaflet from outside the left midclavicular line, with the transducer directed inferiorly and leftward, to be specific for Ebstein's anomaly.

Abnormally late tricuspid valve closure has been thought to be diagnostic of Ebstein's anomaly.$^{6-12}$ 1415 Farooki et al. ${ }^{12}$ found the normal McTc in healthy persons to range from 0 to $0.03 \mathrm{~s}$, and Milner et al. ${ }^{14}$ report normal values from -0.005 to $0.05 \mathrm{~s}$. In both studies, the controls, consisting mostly of patients with congenital malformations with right ventricular volume overload, had McTc not exceeding the normal range (except one case with secundum atrial septal defect and an McTc of $0.06 \mathrm{~s}$ reported by Milner et al. ${ }^{14}$ ). These authors regard a tricuspid valve closure delay of more than $0.03 \mathrm{~s}$ and $0.065 \mathrm{~s}$, respectively, as specific for Ebstein's anomaly. Lundström ${ }^{8}$ in his series of 19 patients considered the upper limit of normal McTc to be $0.03 \mathrm{~s}$; in all his Ebstein patients tricuspid valve closure was late, with McTc at least $0.06 \mathrm{~s}$, the longest interval being $0 \cdot 17 \mathrm{~s}$. In smaller groups of patients with Ebstein's anomaly McTc was $0.04 \mathrm{~s}$ or more. ${ }^{7} 910$

In our group of 11 patients the McTc ranged from 0.04 to $0.14 \mathrm{~s}$ (average $0.09 \pm 0.04 \mathrm{~s}$ ) with a value of $0.06 \mathrm{~s}$ or more in nine cases. Thus, our investigation supports previous evidence that in Ebstein's disease the McTc is usually abnormally prolonged, though (depending on the definition of the upper limit of the normal range) some cases may have normal values of this interval. On the other hand, in more than 8500 echocardiographic

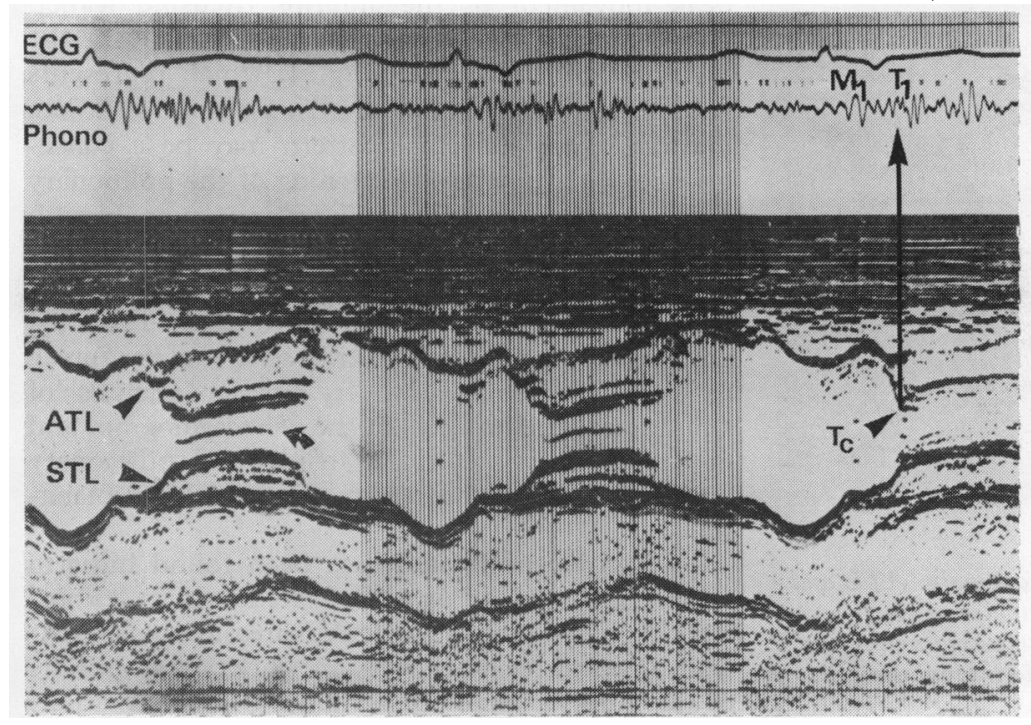

Fig. 3 Echocardiogram in Ebstein's anomaly with tricuspid regurgitation. $A T L$ and $S T L$, anterior and septal tricuspid leaflets. Incomplete systolic closure of the valve with presumably parts of the third leaflet (arrow); $M 1$ and T1, mitral and tricuspid component of the first heart sound. 
studies in our laboratory we have seen only one patient who did not have Ebstein's anomaly but who had McTc between 90 and $120 \mathrm{~ms}$ on several occasions (Fig. 5). This patient was a 2-day-old baby who was shown at necropsy to have pulmonary atresia associated with an intact interventricular septum, patent foramen ovale (diameter $2 \cdot 2 \mathrm{~cm}$ ), persistent ductus arteriosus, enlarged right and small left ventricle, and tricuspid regurgitation. To our knowledge, this is the first time that such a late closure of the tricuspid valve has been described in the absence of Ebstein's anomaly. ${ }^{16}$

The abnormal delay of tricuspid valve closure in patients with Ebstein's anomaly cannot be explained by the presence and degree of right bundle-branch block alone. Late tricuspid closure was observed by Tajik et al. ${ }^{9}$ in one patient with Ebstein's anomaly and WPW syndrome type $B$, but no abnormal delay was found by Milner et al. ${ }^{14}$ in 25 patients with complete right bundle-branch block alone or by Farooki et al. ${ }^{12}$ in 14 patients with atrial septal defect and complete right bundle-branch block. On the other hand, Crews et al. ${ }^{7}$ observed a correlation between width of QRS complex and delay in tricuspid closure in three patients with Ebstein's anomaly and right bundle-branch block. The late closure of the tricuspid valve may be explained by mechanical factors related to the displacement of the enlarged and abnormal tricuspid valve or by an abnormal contraction pattern of the right ventricle. ${ }^{9} 17$

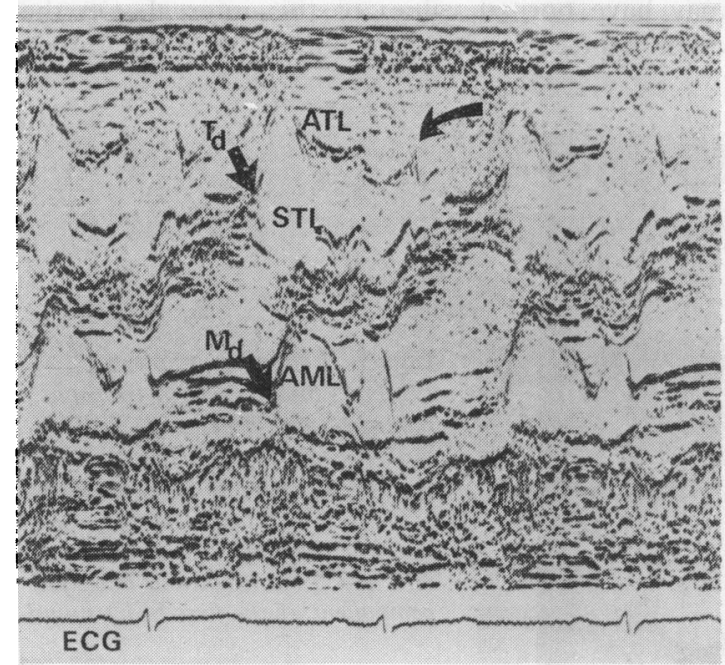

Fig. 4 Echocardiogram in Ebstein's anomaly. ATL and $S T L$, anterior and septal tricuspid leaflets; $A M L$, anterior mitral leaflet; Td and $M d$, tricuspid and mitral valve opening points; curved arrow, additional diastolic opening movement of ATL (see text).

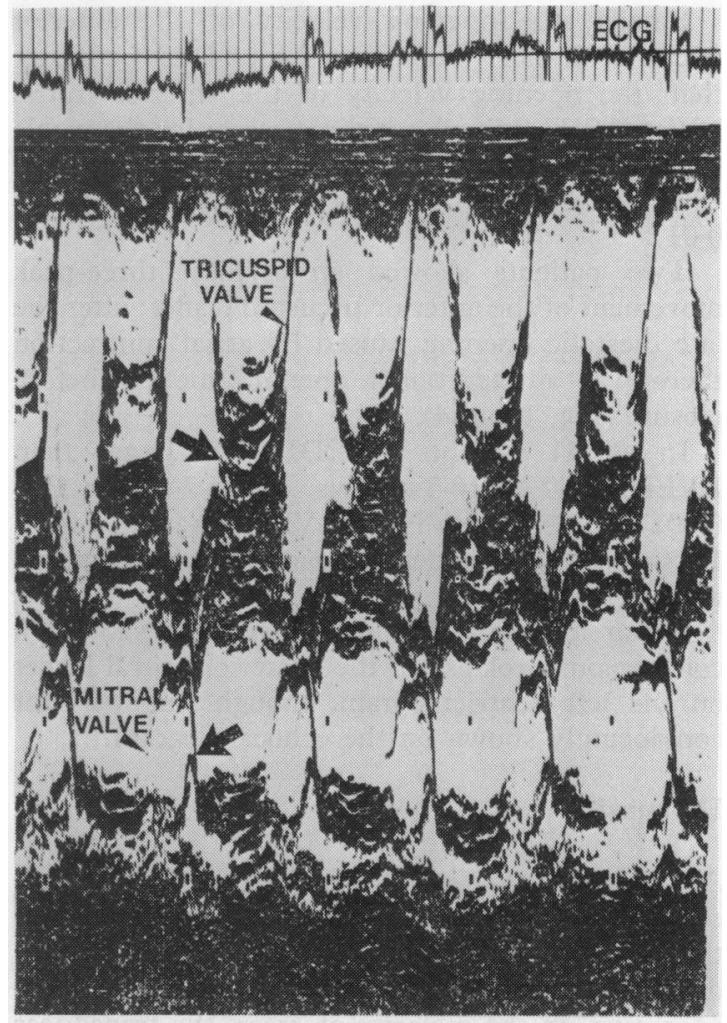

Fig. 5 Echocardiogram of patient with pulmonary atresia without Ebstein's anomaly (proven by necropsy). Tricuspid valve closure follows closure of mitral valve after $0.09 \mathrm{~s}$ (closure points marked by arrows) (see text).

Two patients showed an atypical diastolic threepeak movement of the anterior tricuspid leaflet. The abnormal McTc in these was obviously the result of the third peak (Fig. 4) which represents an additional opening of the tricuspid valve in late diastole. This abnormal pattern may be a consequence of the premature opening of the pulmonary valve described in cases of Ebstein's anomaly with tricuspid regurgitation. ${ }^{18}$ It is possible that the premature pulmonary opening and the resulting right ventricular pressure changes cause a divided opening movement of the tricuspid leaflets during atrial contraction. However, further analysis of simultaneous recordings of the echocardiogram and of pressures in the right atrium and pulmonary artery would be necessary to confirm this explanation.

No significant relation has been found hitherto between McTc and age, associated cardiac lesions, right atrial or right ventricular pressure or dimension, opening velocity, closing slope, or amplitude of the anterior tricuspid leaflet.12 Our observations 
confirm these findings in respect of amplitude, opening velocity, closing slope, and RVEDD.

Amplitude, opening velocity, and closing slope of the anterior tricuspid leaflet and the relation of these measurements to the corresponding values of the anterior mitral leaflet do not distinguish patients with Ebstein's anomaly from normals and those with other congenital malformations of the heart. ${ }^{12}$ In our patients also these measurements show a wide scatter and overlap with the control values.

Lundström ${ }^{8}$ found an abnormally anterior position of the anterior tricuspid leaflet in his patients with Ebstein's malformation and considered this to be specific and diagnostic. We could not confirm this observation in our patients; this may be explained by a different transducer position.

Like Farooki et al., ${ }^{12}$ we were unable to confirm the diagnostic value of an anterior tricuspid leaflet amplitude twice that of the anterior mitral leaflet, or an increased closing slope of the anterior tricuspid leaflet. ${ }^{6}$

Lundström $^{8} 15$ and Farooki et al. ${ }^{12}$ observed a delayed or (in a few cases) simultaneous opening of the anterior tricuspid leaflet (point $\mathrm{Td}$ ) relative to opening of the anterior mitral leaflet. Three of our patients (Fig. 4) showed a negative MdTd ( $-0 \cdot 2$ to $-0.06 \mathrm{~s}$ ); however, in all these three cases McTc was prolonged $(0.09$ to $0.11 \mathrm{~s})$. If one ignores the difficulty in locating the point ' $d$ ' precisely in certain cases, these observations reflect the variable anatomical and echocardiographic features of Ebstein's anomaly.

In patients with Ebstein's malformation normal or abnormal septal movement may be found. ${ }^{810} 12$ The relation between the sizes of the right and left ventricles seems to be important in this context. All our patients showed a paradoxical septal movement type $A$ and in all cases the right ventricular diameter was larger than the diameter of the left ventricle. One of our patients showed mitral valve prolapse on the left ventriculogram. To our knowledge, this has been reported previously in only seven cases with Ebstein's anomaly. ${ }^{19} 20$ The diagnosis of mitral valve prolapse is difficult in this disease because the murmur of tricuspid regurgitation and the split first heart sound of Ebstein's anomaly mask the typical auscultatory findings of mitral prolapse; moreover, in these cases the mitral valve apparatus is sometimes difficult to record echocardiographically, and during cardiac catheterisation left ventriculography is seldom performed.

Our findings and those recorded in earlier published reports show that Ebstein's anomaly can be diagnosed by echocardiography in many cases. Simultaneous recording of the tricuspid and mitral valves with a transducer position outside the left midclavicular line may be a clue to the diagnosis, and a tricuspid closure delay of $0.065 \mathrm{~s}$ and more may be considered as diagnostic, since exceptions are very rare. Our results support the view that echocardiography, with clinical examination, makes it possible to avoid the relatively high risk of cardiac catheterisation in Ebstein's anomaly, particularly in those patients with mild or severe forms of the disease for whom surgical treatment is not being considered.

\section{References}

${ }^{1}$ Ebstein W. Ueber einen sehr seltenen Fall von Insufficienz der Valvula tricuspidalis, bedingt durch eine angeborene hochgradige Mißbildung derselben. Arch Anat Physiol Wissenschaftl Med 1866; 33: 238-54.

${ }^{2}$ Keith JD, Rowe RD, Vlad P. Heart disease in infancy and childhood. New York: Macmillan, 1958: 314.

${ }^{3}$ Vacca JB, Bussmann DW, Mudd JG. Ebstein's anomaly. Complete review of 108 cases. Am f Cardiol 1958; 2: 210-26.

${ }^{4}$ Schiebler GL, Adams P Jr, Anderson RC, Amplatz K, Lester RG. Clinical study of twenty-three cases of Ebstein's anomaly of the tricuspid valve. Circulation 1959; 19: 165-87.

${ }^{5}$ Watson H. Natural history of Ebstein's anomaly of tricuspid valve in childhood and adolescence. An international cooperative study of 505 cases. Br Heart f 1974; 36: 417-27.

${ }^{6}$ Kotler MN, Tabatznik B. Recognition of Ebstein's anomaly by ultrasound technique (abstract). Circulation 1971; 43/44: Suppl. II : 34.

${ }^{7}$ Crews TL, Pridie RB, Benham R, Leatham A. Auscultatory and phonocardiographic findings in Ebstein's anomaly. Correlation of first heart sound with ultrasonic records of tricuspid valve movement. $\mathrm{Br}$ Heart $\mathcal{F} 1972$; 34: 681-7.

${ }^{8}$ Lundström NR. Echocardiography in the diagnosis of Ebstein's anomaly of the tricuspid valve. Circulation 1973; 47: 597-605.

${ }^{9}$ Tajik AJ, Gau GT, Giuliani ER, Ritter DG, Schattenberg TT. Echocardiogram in Ebstein's anomaly with Wolff-Parkinson-White pre-excitation syndrom, type B. Circulation 1973; 47: 813-8.

${ }^{10}$ Yuste $P$, Minguez I, Aza V, Señor J, Asin E, MartinezBordiu C. Echocardiography in the diagnosis of Ebstein's anomaly. Chest 1974; 66: 273-7.

${ }^{11}$ Kotler MN. Tricuspid valve in Ebstein's anomaly. Circulation 1974; 49: 194.

${ }^{12}$ Farooki ZQ, Henry JG, Green EW. Echocardiographic spectrum of Ebstein's anomaly of the tricuspid valve. Circulation 1976; 53: 63-8.

${ }^{13}$ Matsumoto M, Matsuo H, Nagata S et al. Visualization of Ebstein's anomaly of the tricuspid valve by twodimensional and standard echocardiography. Circulation 1976; 53: 69-79.

${ }^{14}$ Milner S, Meyer RA, Venables AW, Korfhagen J, Kaplan S. Mitral and tricuspid valve closure in congenital heart disease. Circulation 1976; 53: 513-8. 
${ }^{15}$ Lundström NR. Reflected ultrasound in the diagnosis of congenital heart disease. In: Proceedings of the 1st world congress on ultrasonic diagnostics in medicine. Vienna 1971, vol. 3. Vienna: Wiener Medizinischen Akademie, 1969: 395-405.

${ }^{16}$ Gisbertz R, Luhmer I, Kallfelz HC. Pathologic tricuspid valve closure delay in non-Ebstein disease. In preparation.

${ }^{17}$ Fontana ME, Wooley CF. Sail sound in Ebstein's anomaly of the tricuspid valve. Circulation 1972; 46: 155-64.

${ }^{18}$ Wann LS, Weyman AE, Dillon JC, Feigenbaum H. Premature pulmonary valve opening. Circulation 1977; 55: 128-33.
${ }^{19}$ Roberts WC, Glancy DL, Seningen RP, Maron BJ, Epstein SE. Prolapse of the mitral valve (floppy valve) associated with Ebstein's anomaly of the tricuspid valve. Am $\mathcal{F}$ Cardiol 1976; 38: 377-82.

${ }^{20}$ Monibi AA, Neches WH, Lenox CC, Park SC, Mathews RA, Zuberbuhler JR. Left ventricular anomalies associated with Ebstein's malformation of the tricuspid valve. Circulation 1978; 57: 303-6.

Requests for reprints to Dr Werner Daniel, Division of Cardiology, Department of Medicine, Medical School Hannover, Karl-Wiechert-Allee 9, 3000 Hannover 61, West Germany. 